Adverse Drug Reactions Advisory Committee, Uppsala, for their permission to publish material from their files. This study was in part supported by grant 3880 from the Swedish Medical Research Council.

\section{References}

1 Opie LH. Drugs and the heart four years on. Lancet 1984 ; i:496-500

2 Jones RFM, Hammond VT, Wright D, Ballantyne JC. Practolol and deafness.

F Laryngol Otol 1977;91:963-72.
Lidén G. Speech audiometry, an experimental and clinical study with Swedish language material. Acta Otolaryngol 1954; suppl 114

4 Pritchard JF, Schneck DW, Hayes AH Jr. Determination of propranolol and six metabolites in human urine by high-pressure liquid chromatography. $\mathcal{F}$
Chromatogr 1979;162:47-58.
5 Yee Y-G, Rubin P, Blaschke TF. Atenolol determination by high-performance liquid chromatography and fluorescence detection. I Chromatogr 1979;171 357-62.

6 Scales B, Copsey PB. The gas chromatographic determination of atenolol in biological samples. F Pharm Pharmacol 1975;27:430-3.

7 Lennard MS, Silas JH, Smith AJ, Tucker GT. Determination of debrisoquine and its 4-hydroxy metabolite in biological fluids by gas chromatography with flame-ionization and nitrogen-selective detection. F Chromatogr 1977;133:161-6. 8 Savola J. Arthropathy induced by beta blockade. Br Med f 1983;287:1256-7.

9 Etholm B, Belal A Jr. Senile changes in the middle ear joints. Ann Otol Rhinol Laryngol 1974;83:49-54.

10 Weber JCP. Beta-adrenoreceptor antagonists and diplopia. Lancet 1982 ;ii :826. 1 Blom S, Zakrisson JE. The stapedius reflex in the diagnosis of myasthenia gravis. $\mathcal{F}$ Neurol Sci 1974;21:71-6.

12 Pirrotta JA, Fraser DG. Aspirin or nadolol-induced hearing loss. Drug Intell Clin Pharm 1982;16:748.

(Accepted 6 September 1984)

\title{
Influence of non-steroidal anti-inflammatory drugs on diuretic treatment of mild to moderate essential hypertension
}

\author{
P P KOOPMANS, TH THIEN, F W J GRIBNAU
}

\begin{abstract}
In an open triple crossover study in 10 patients with mild to moderate essential hypertension the influence was investigated of adding indomethacin $50 \mathrm{mg}$, naproxen $250 \mathrm{mg}$, or sulindac $200 \mathrm{mg}$, each twice daily for four weeks, to diuretic treatment with hydrochlorothiazide $50 \mathrm{mg}$ a day.

After two weeks' treatment with indomethacin a slight increase in blood pressure was observed, whereas both sulindac and naproxen tended to enhance the antihypertensive effect of hydrochlorothiazide. After treatment for four weeks, however, the effects of all three drugs on blood pressure appeared to be blunted. Furthermore, body weight increased significantly during treatment with indomethacin but not during treatment with naproxen or sulindac. No significant changes were found for various biochemical variables, including concentrations of plasma electrolytes and serum creatinine and albumin, plasma renin activity, plasma aldosterone concentration, and 24 hour urinary excretion of sodium and potassium, with the exception, however, of an increase in plasma potassium concentration during treatment with indomethacin.

These observations suggest that the interaction of indomethacin, naproxen, and sulindac with diuretic treatment in mild to moderate essential hypertension is transient and of minor clinical importance.
\end{abstract}

\section{Introduction}

Although several investigations have shown that inhibition of the synthesis of prostaglandins in the kidney by non-steroidal antiinflammatory drugs can blunt the natriuretic response during

Department of Medicine, Division of General Internal Medicine, Sint Radboudhospital, PO Box 9101, Nijmegen, The Netherlands P P KOOPMANS, MD, internist

TH THIEN, MD, internist

F W J GRIBNAU, MD, professor of clinical pharmacology

Correspondence and requests for reprints to: Dr P P Koopmans. diuretic treatment, particularly in states of high angiotensin II concentrations, ${ }^{1-6}$ published findings have agreed less on whether non-steroidal anti-inflammatory drugs can influence, in a clinically important way, the antihypertensive effect of thiazide diuretics. Several authors have reported attenuation of the effect of thiazide diuretics and other antihypertensive drugs on blood pressure as a result of indomethacin treatment in patients with hypertension. ${ }^{7-11}$ For instance, when indomethacin was added to various antihypertensive drugs an increase of $14 / 6 \mathrm{~mm} \mathrm{Hg}$ in supine blood pressure was observed ${ }^{8}$ and even of $13 / 9 \mathrm{~mm} \mathrm{Hg}$ in patients treated with only thiazide diuretics. ${ }^{7}$ On the other hand, Steiness found only a slight (and not significant) increase in blood pressure during treatment with indomethacin but an additional decrease during treatment with sulindac. ${ }^{12}$ As sulindac is supposed to have less effect on renal prostaglandin synthesis than any other non-steroidal anti-inflammatory drug, ${ }_{13}^{14}$ it might have advantages in hypertensive patients receiving diuretics who need non-steroidal anti-inflammatory drugs for osteoarthritis or other rheumatic diseases.

Here we report the results of the treatment of 10 patients with essential hypertension with hydrochlorothiazide alone and hydrochlorothiazide in combination with indomethacin, naproxen, or sulindac.

\section{Patients and methods}

Ten patients (eight men, two women), aged 21-65 (mean (SD) 48.4 (11.3)) years, with essential hypertension, were selected from the outpatient clinic for study. We included patients with untreated supine diastolic blood pressure greater than $85 \mathrm{~mm} \mathrm{Hg}$. None of the patients had secondary hypertension, signs or symptoms of congestive heart failure, aortic valve dysfunction, or history of peptic ulcer. All patients gave their informed consent, and the local ethics committee approved the protocol.

The trial was designed as an open triple crossover study lasting for 28 weeks. After a washout period of four to eight weeks, in which all other antihypertensive treatment was stopped, treatment with hydrochlorothiazide $50 \mathrm{mg}$ a day was started. Then, successively, indomethacin $50 \mathrm{mg}$ twice daily, naproxen $250 \mathrm{mg}$ twice daily, and sulindac $200 \mathrm{mg}$ twice daily were added for four weeks in random sequence, and always with an intermediate washout period of four weeks in which hydrochlorothiazide alone was continued.

Every two weeks the patients visited the outpatient clinic for measurement of supine and standing blood pressure, pulse rate, and 
body weight. Every four weeks a venous blood sample was drawn for determining concentrations of plasma electrolytes, serum creatinine serum albumin, and plasma aldosterone and plasma renin activity. Furthermore, the patients were asked to collect 24 hour samples of urine for measuring the excretion of sodium, potassium, and creatinine at the end of each period of treatment. Blood pressure was measured in patients, when supine, on the right arm at intervals of two minutes over 25 minutes with the arteriosonde 1217 . For evaluation, means of all readings were calculated leaving out the first two and the last readings. At the end of the automatic measurements blood pressure was determined twice with a legally stamped sphygmomanometer on the left arm both in supine and standing positions. Phase $\mathrm{V}$ of the Korotkoff sounds was considered to be the diastolic blood pressure. The mean arterial pressure was calculated as the sum of the diastolic blood pressure and one third of the pulse pressure.

Patient compliance was established by pill counts every two weeks, which showed a mean of $99 \%$ for both hydrochlorothiazide (range 86-100\%) and non-steroidal anti-inflammatory drugs (range 89-100 ${ }^{\circ}$ ). Plasma aldosterone concentration and renin activity were determined by radioimmunoassay. ${ }^{1516}$

Statistical analysis was performed with an analysis of variance for a three period Latin square design; $p<0.05$ was considered to be significant. All data are presented as means (SD) unless indicated otherwise.

\section{Results}

Mean supine blood pressure, as measured by sphygmomanometer, fell during the initial period of treatment with hydrochlorothiazide alone (weeks 1-4) from a baseline value of $143 \cdot 0 / 98 \cdot 5(12 / 7) \mathrm{mm} \mathrm{Hg}$ to $133 / 93(12 / 7) \mathrm{mm} \mathrm{Hg}$ at week 4 ; the values for the arteriosonde measurements were, however, $136 \cdot 2 / 98 \cdot 5(11 / 8) \mathrm{mm} \mathrm{Hg}$ and $127 / 91 \cdot 7$ $(13 / 7) \mathrm{mm} \mathrm{Hg}$, respectively. During all the subsequent phases of treatment with hydrochlorothiazide alone the mean blood pressure, measured either by sphygmomanometer or by arteriosonde, remained within 2 or $3 \mathrm{~mm} \mathrm{Hg}$ of the values reported in the first period. In addition there were no significant differences between the values measured at week 2 and at week 4 of each period.

Mean body weight decreased from $73.6(12.0) \mathrm{kg}$ initially to 72.5 $(12.0) \mathrm{kg}$ at week 4 and was not statistically different in the phases with hydrochlorothiazide alone. Figure 1 shows the mean supine blood pressure, measured by sphygmomanometer and arteriosonde, and the mean proportional $\left({ }^{0} 0\right)$ change in body weight, as compared with baseline values, during treatment with indomethacin, sulindac, and naproxen in addition to hydrochlorothiazide, with the values at the end of their preceding phases of treatment with hydrochlorothiazide alone. Compared with hydrochlorothiazide alone, concomitant treatment with indomethacin tended to increase blood pressure at weeks 2 and 4 and treatment with either sulindac or naproxen showed slight decreases. At week 2 significantly higher values for indomethacin $(p<0.05)$, when compared with either sulindac or naproxen, were observed for supine blood pressure. At week 4 , however, no significant differences were observed; instead mean blood pressure values for all combination treatments tended to revert to values at the end of the phases with hydrochlorothiazide alone. Furthermore, a significant increase in body weight was observed during treatment with indomethacin both after two and four weeks $(p<0.05)$, whereas naproxen and sulindac induced no significant changes in body weight.

Figure 2 shows the individual mean arterial pressures measured by sphygmomanometer during the different phases of treatment. A considerable variation in mean arterial pressure response was observed, but overall blood pressure increased in most (seven) patients during indomethacin treatment for two weeks, but fell or showed no response

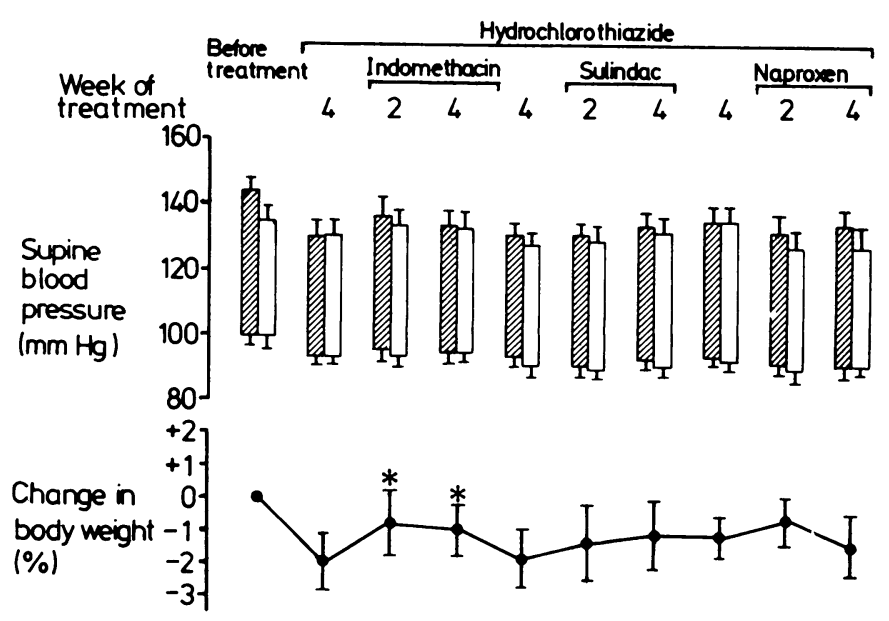

FIG 1 - Mean (SD) supine blood pressure ( $\mathrm{mm} \mathrm{Hg}$ ) measured by sphygmomanometer $\square$ and arteriosonde $\square$ and proportional changes in body weight, compared with baseline values, in 10 patients during treatment with indomethacin, sulindac, and naproxen in addition to hydrochlorothiazide at two and four weeks. Mean blood pressure at week 4 during preceding period of treatment with hydrochlorothiazide alone is also shown.

* $\mathrm{p}<0.05$ compared with hydrochlorothiazide alone.

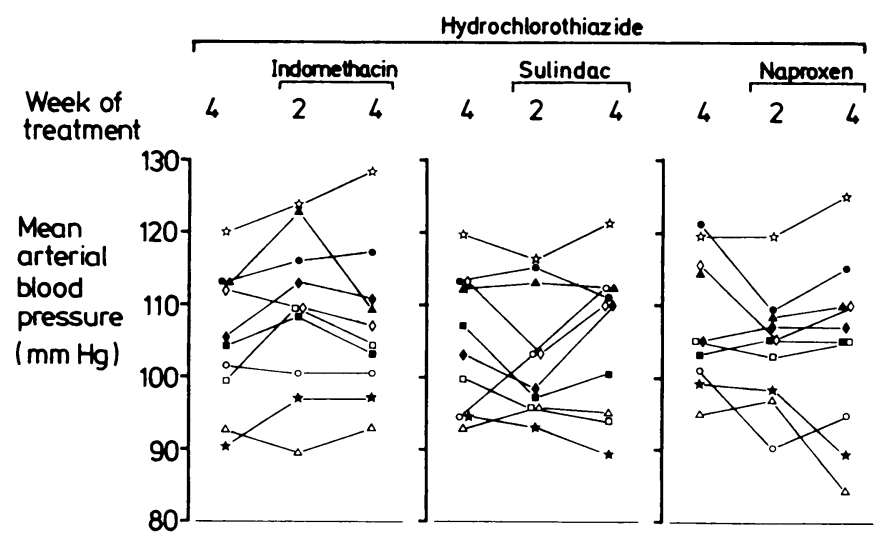

FIG 2-Mean arterial blood pressure for each patient during weeks 2 and 4 of treatment with indomethacin, naproxen, and sulindac in combination with hydrochlorothiazide, and mean arterial blood pressure during preceding period of treatment with hydrochlorothiazide alone.

with either sulindac or naproxen in six and seven patients respectively. At week 4 blood pressures tended to revert to their initial values, although they remained variable.

The table shows plasma potassium concentration, plasma aldosterone concentration, plasma renin activity, serum albumin concentration, endogenous creatinine clearance, and 24 hour urinary excretion of sodium and potassium at the start of the study, at the end of each phase with combination treatment, and at the end of each preceding phase with hydrochlorothiazide alone. Compared with values at the start of the study plasma potassium concentration decreased significantly $(p<0.005)$ and plasma aldosterone concentration increased significantly $(\mathrm{p}<0.05)$, as did plasma renin activity $(\mathrm{p}<0.01$; Wilcoxon 
test) after treatment with hydrochlorothiazide alone. No significant differences in albumin concentration, endogenous creatinine clearance, or 24 hour urinary excretion of sodium and potassium were observed. Moreover, significant changes were found in none of the variables during treatment with any of the non-steroidal anti-inflammatory drugs compared with values during treatment with hydrochlorothiazide alone, with the exception of an increase in plasma potassium concentration $(p<0.05)$ during treatment with indomethacin.

\section{Discussion}

In this three way crossover study we found that addition of a non-steroidal anti-inflammatory drug, such as indomethacin, naproxen, or sulindac, did not influence in a clinically important way the antihypertensive effect of hydrochlorothiazide. Our data contradict the results of some other studies. ${ }^{7} 817$ Several factors could be responsible for this difference, for instance differences in study design, time effects, dosages, or methods of measuring blood pressure.

An increase in blood pressure has previously been observed when indomethacin was added for one week to diuretic treatment in hypertensive patients. ${ }^{14}$ Longer periods of up to six weeks ${ }^{7} 8$ have also been used to show an interaction between diuretics and non-steroidal anti-inflammatory drugs. We therefore chose in our three way crossover study to give each non-steroidal antiinflammatory drug for four weeks; on the one hand this time span had been confirmed to be sufficiently long and on the other this could also elicit a temporary interaction. Moreover, washout periods, also consisting of four weeks, were used to prevent carry over effects and to provide for similar blood pressure values at the beginning of each period of treatment with non-steroidal anti-inflammatory drugs.

Our results may indeed suggest a transient interaction: the addition of indomethacin for two weeks induced a slight increase $(6 / 3 \mathrm{~mm} \mathrm{Hg})$ in blood pressure and that of naproxen or sulindac tended to enhance the antihypertensive effect of hydrochlorothiazide, but, after four weeks' treatment with any of the three non-steroidal anti-inflammatory drugs their effects appeared to be blunted, for blood pressure values reverted to baseline. In agreement with other investigators, ${ }^{217}$ we also observed considerable individual variations in blood pressure during treatment with non-steroidal anti-inflammatory drugs.

In accordance with published findings, adding indomethacin to diuretic treatment increased body weight and attenuated the decrease in plasma potassium concentration by hydrochlorothiazide. ${ }^{1-5}$ No other significant changes were observed for various biochemical variables.

One disadvantage of this study may have been its open character, as compared with some double blind placebo controlled studies. ${ }^{7}$ \& In contrast to these, however, we used a strictly prospective design and we measured blood pressure in each period of four weeks on two occasions with both a sphygmomanometer (the subjective method), and an arteriosonde (the objective method), being a blind method. Moreover, we emphasise that these values gained by arteriosonde were means of eight readings per patient on each occasion.

We cannot exclude that higher dosages of the three nonsteroidal anti-inflammatory drugs might have shown an important interaction with hydrochlorothiazide. An increase in blood pressure, however, has been shown with a dosage of indomethacin similar to that used here. ${ }^{7}$ Conversely, the dosages of the three non-steroidal anti-inflammatory drugs were usual for the treatment of osteoarthritis and arthritic disorders. Thus higher dosages would not have been appropriate for the purpose of this study, which was to investigate whether non-steroidal anti-inflammatory drugs influence the treatment of hypertension when these drugs are necessary for concomitant locomotor diseases.

From a theoretical point of view sulindac might be preferred as the non-steroidal anti-inflammatory drug of choice in patients treated with thiazides as it showed possibly minor effects on renal prostaglandin synthesis ${ }^{13} 1418$ compared with indomethacin and naproxen. ${ }^{1}$ This study, however, did not establish the clinical relevance of this difference as addition of all three non-steroidal anti-inflammatory drugs to hydrochlorothiazide resulted only in marginal and transient effects on blood pressure.

We thank Mrs G Wessel for preparing the manuscript. This study was supported by a grant from Merck Sharp and Dohme, Haarlem, The Netherlands.

This paper is dedicated to Professor E J Ariens on the occasion of his retirement.

\section{References}

1 Lifschitz MD. Renal effects of nonsteroidal antiinflammatory agents. $f$ Lab Clin Med 1978;102:313-2

2 Levenson DJ, Simmons CE, Brenner BM. Arachidonic acid metabolism, prostaglandins and the kidney. Am $\mathcal{A}$ Med $1982 ; 72: 354-74$.

Tan SY, Mulrow PJ. Inhibition of the renin-aldosterone response to furosemide by indomethacin. $f$ Clin Endocrinol Metab 1977;45:174-6.

, kaliure

5 Valloton MB, Favre L Classon Ph. Agents anti-inflammatoires non-steroïdiens, diurétiques et fonction renale: une mise en garde. Schweiz Med Wochenschr 1983;113:1198-201.

6 Epstein M, Lifschitz MD. Volume status as a determinant of the influence of

7 Watkins J, Abbott EC, Hensby CN, Webster J, Dollery CT. Attenuation of hypotensive effect of propranolol and thiazide diuretics by indomethacin. $\mathrm{Br}$ Med f 1980;281:702-5.

8 Wing LMH, Bune AJC, Chalmers JP, Graham JR, West MJ. The effects of ndomethacin in

9 Pedrinelli R, Magagna A, Salvetti A. The effects of oxprenolol and indomethacin on renin and aldosterone of normal subjects during low sodium diet. Eur $\mathcal{F}$ Clin Invest $1982 ; 12: 107-11$.

10 Salvetti A, Arzilli F, Pedrinelli R, Beggi P, Motolese M. Interaction between oxprenolol and indomethacin on blood pressure in essential hypertensive patients. Eur f Clin Pharmacol 1982;22:197-201.

11 Fujita T, Yamashita N, Yamashita K. Effect of indomethacin on antihypertensive action of captopril in hypertensive patients. Clin Exp Hypertens $[A] 1981 ; 3$ 939-52.

12 Steiness $\mathrm{E}$. Different interactions of indomethacin and sulindac with thiazides in hypertension. Br Med $\mathcal{F} 1982 ; 285: 1702-3$.

13 Ciabattoni G, Pugliese F, Cinotti GA, Patrono C. Renal effects of antiinflammatory drugs. Eur $\mathcal{F}$ Rheumatol Inflamm 1980;3.210-21.

14 Ciabatoni G Cinotti GA, Pierucci A, et al. Effects of sulindac and ibuprofen in patients with chronic glomerular disease: evidence for the dependence of renal patients with chronic glomerular disease: evidence for the
function on prostacyclin. $N$ Engl $₹$ Med $1984 ; 310: 279-84$.

15 Man AJM de, Hofman JA, Hendriks Th, Rosmalen FMA, Ross HA, Benraad ThJ. A direct radioimmunoassay for plasma aldosterone: significance of endogenous cortisol. Neth $\mathcal{f}$ Med 1980;23:79.

16 Drayer JIM, Benraad ThJ. The reliability of the measurement of plasma renin activity by radioimmunoassay. Clin Chim Acta 1975;61:309.

17 Lopez-Ovejero JA, Weber MA, Drayer JIM, Scaley JE, Laragh JH. Effects of indomethacin alone and during diuretic or $\beta$-adrenoreceptor-blockade therapy on blood pressure and the renin system in essential hypertension. Clinical Science and Molecular Medicine $1978,55: 203-5$.

8 Kimberley RP, Bowden RE, Keiser HR, Klotz PH. Reduction of renal function by newer non-steroidal anti-inflammatory drugs. Am $\mathcal{F}$ Med 1978;64:804.

(Accepted 7 September 1984) 